La genealogía de un desencuentro

doi: 10.11144/Javeriana.uph36-72.gdud

\title{
Reseña a Nibilismo y verdad. Nietzsche en América Latina de Alejandro Sánchez Lopera
}

La historia de la filosofía local, nacional y regional en América Latina se agotó con la proliferación de los modelos épicos y europeístas, conectados a un exangüe ejercicio de contextualización. Tales historias de la filosofía se desarrollaron según las líneas de la historia de las ideas que promovió buena parte del proyecto intelectual conocido como filosofía latinoamericana. En su mayoría, este tipo de historias limitaron la actividad filosófica del subcontinente al siglo XX (acaso unas pocas décadas atrás); y ello, a pesar de que existen registros continuados de producción filosófica en la región que vienen del siglo XVII. Estas historias, además, insistieron en señalar un déficit o un retraso de la filosofía local en relación con la producción filosófica europea.

En su libro, Sánchez Lopera nos muestra que la limitada comprensión de la actividad filosófica en América Latina promovida por la historia de la filosofía tiene su correlato en el ejercicio hegemónico de la filosofía en la región; incluida aquella con pretensiones universalistas que buscó distanciarse de la filosofía latinoamericana, otro proyecto filosófico que hoy conocemos con el problemático término de normalización. No fue, sin embargo, un diagnóstico general de la actividad filosófica en América Latina lo que condujo a Sánchez Lopera a señalar el agotamiento de la historia de la filosofía latinoamericana; fue el recorrido por la obra de algunos de los lectores regionales de Nietzsche.

Ese recorrido lo llevó a mostrar que, en América Latina, Nietzsche fue leído tardíamente. No obstante, esa demora no debe entenderse como producto de un atraso, en el sentido teleológico de lo que debería haberse alcanzado en un momento del pasado, pero no fue. El desfase temporal es, más bien, un desencuentro entre los filósofos de esta parte del mundo y la obra de Nietzsche. Desencuentro que, en su nivel determinante, consistió en la incompatibilidad de las tesis de la obra nietzscheana con los deseos, proyectos y valoraciones que caracterizaron a 
diversos tipos de producción filosófica latinoamericana, por ejemplo, hacer parte de la filosofía universal, identificar el origen de la filosofía local, ponerse al día con las corrientes de pensamiento internacional.

La novedad de este punto de mira, el del desencuentro, le exigió al autor de Nibilismo y verdad tomar distancia de esos modos de contar la historia de la filosofía latinoamericana, rechazar la separación a priori entre latinoamericanistas y normalizadores y evitar preguntas clásicas de la filosofía de la región como las que gravitan en torno al ser latinoamericano o a la mixtura cultural. Este trabajo en torno al desencuentro implicó, además, poner en diálogo la producción filosófica latinoamericana con dos tradiciones: la europea de lectura de la obra de Nietzsche y la crítica literaria latinoamericana del siglo XX. Esta triangulación de tradiciones está atravesada por tres grandes temas: el cuerpo, la escritura y la historia. De este modo, se dibuja una ruta metodológica que evidencia su provecho en la tesis misma del desencuentro como clave de lectura de un corpus disperso por la región y no siempre fácil de articular.

Para Sánchez Lopera, este desencuentro es constitutivo de la obra de Nietzsche en su relación con Europa y particularmente con la moral ilustrada, fundada en la autonomía y libertad del individuo y "al lado de la cual, delante de la cual, detrás de la cual -Nietzsche sostiene, según nos recuerda Sánchez Lopera (2008)son o deberían ser posibles muchas otras morales" (p. 1). El segundo nivel de este desencuentro es el ya mencionado desencuentro temporal, pues si se compara con otros filósofos, "Nietzsche no parece haber sido convidado a América Latina [...]. Es curioso ver cómo frente a los diversos estudios y debates sobre la compleja situación de Marx y Freud en América Latina, los estudios de recepción de Nietzsche hayan tardado tanto" (Sánchez Lopera, 2018, p. 2). En este respecto, se puede señalar que, a pesar de que en la región sí se leyó a Nietzsche, no se lo asumió en concordancia con la naturaleza de su obra: "con Nietzsche el problema no es el del sistema referencial del autor, sino el del estilo: Nietzsche es una perspectiva" (Sánchez Lopera, 2018, p. 4). Por último, en su nivel determinante, el desencuentro es un destiempo:

Destiempo que concibo no como resultado de la ausencia de una comunidad académica establecida, rezagada frente a la europea, sino como síntoma de un dilema moral. Ese destiempo, o desfase, lo entiendo como un 
desencuentro entre América Latina y Nietzsche. Es decir que no me enfoco en una historia académica-institucional, estudiando a las figuras mayores de la difusión de Nietzsche en Latinoamérica, sino en los hábitos morales que llevan a ese desencuentro; de ahí quizás parta una posible explicación de su recepción "tardía" en América Latina. Este impasse entre Nietzsche y América Latina, no como lapsus, falta o equivocación cometida por descuido, sino como compás de espera, ofrece el tiempo necesario para pensar, no para juzgar. Eso, de paso, permite evitar entender ese retraso temporal como déficit (Sánchez Lopera, 2018, p. 10).

Estos tres niveles del desencuentro como punto de mira para una historia de la relación de la filosofía latinoamericana con Nietzsche habilitan la formulación de una historia en clave de síntomas y hábitos morales, de confrontaciones entre formas de moralidad; esto es, habilitan un trabajo genealógico en el más estricto sentido del término. Como se ve, Nietzsche, además de operar como un tema, opera como un método. Dicho desde otro ángulo, Nibilismo y verdad no es simplemente el resultado de un trabajo de archivo maquillado de "genealogía”; aquí nos encontramos ante la elaboración de la pregunta por nuestros valores morales y con la exigencia tanto de una valoración de lo observado, como de una reescritura de nosotros mismos en el ámbito de la filosofía y la historia de la filosofía en y sobre América Latina. La relación compleja entre el tema y la dimensión genealógica del trabajo es presentada por Sánchez Lopera (2018) del siguiente modo:

Mi tesis es que, en tanto pensamiento de lo uno, la filosofía latinoamericana no puede servirse del pensamiento nietzscheano: es imposible construir un pensamiento del origen y la unidad desde un pensamiento de lo múltiple, como el de Nietzsche. Es decir, América Latina hubiera sido una experiencia insostenible, en términos discursivos y no discursivos, en caso de haberse encontrado con Nietzsche. Hubiera disuelto su unidad. Así, en vez de usar a Nietzsche para analizar su moral, para desplazar el punto de vista, en América Latina se moraliza a Nietzsche al ponerlo al servicio de esa moral, dejándola indemne. Con Nietzsche se abre un juego de ópticas en lugar de un texto de significantes o discursos del pensamiento latinoamericano. Finalmente, el libro aparece como algo más allá del continente y el contenido: el análisis nietzscheano de 
la culpa y el nihilismo permite deshacer la fascinación latinoamericana con lo auténtico y exclamar: ¡no más el libro de América Latina! (p. 7)

Esta voluntad genealógica de Sánchez Lopera le permite superar el punto de vista del déficit diagnosticado por las historias de la filosofía latinoamericana ${ }^{1} \mathrm{y}$ abrirse a perspectivas inéditas de lectura de esa historia. Perspectivas que determinan su mirada de las corrientes latinoamericanas de pensamiento filosófico que se autodeclararon nietzscheanas; que inciden en su lectura de la obra de autores como José Ortega y Gasset y enmarcan su comprensión de escuelas filosóficas como la hermenéutica - la cual, llegada por la vía de Ortega y Gasset y su relación con los trabajos de Wilhelm Dilthey, habría sido uno de los motores del desencuentro entre Nietzsche y América Latina a lo largo de todo el siglo XX-; incluso que definen la conexión que Sánchez Lopera establece entre Nietzsche y algunas tendencias político-filosóficas como los socialismos y los comunismos latinoamericanos.

Sin duda, se trata de un trabajo relevante para la historia de la filosofía y la historia de la recepción de la obra de autores europeos en América Latina, pero también es relevante para el ejercicio mismo de la filosofía en la región; no solo da una interpretación de su pasado, sino que señala los caminos para comenzar a pensar más allá del desencuentro señalado y hacer rendir en la historia local un método filosófico. A sus ámbitos de relevancia debe sumarse el que la prosa de Sánchez Lopera fluye a buen ritmo, a pesar de su apariencia fragmentaria; apariencia que quizá sea el efecto del vadeo, muchas veces prolongado, de los meandros y ramales de la tradición de lectura de Nietzsche a lado y lado del Atlántico. Camino sinuoso, cargado de aparentes digresiones enigmáticas, que por momentos parece evasivo pero que, al final, termina por encontrar el cauce original del que partió.

Entre las limitaciones de Nibilismo y verdad, se cuenta la relación irregular con su lector. Al comienzo, el trabajo exige un conocimiento íntimo de la obra de Nietzsche. Luego de un par de secciones, sin embargo, el autor se extiende en explicaciones de la lectura de Nietzsche en un estilo casi, podría decirse,

1 Punto de vista que en otro lugar he llamado "marco de referencia de la modernidad" (López, 2018, pp. 49-99). 
propedéutico. Se siente allí que hay quizás demasiado Nietzsche y lecturas europeas de Nietzsche frente al corpus latinoamericano que, cuando no se trata del proyecto de una filosofía latinoamericana, es más bien escaso. De allí que, a pesar del título y de la lucidez de sus lecturas de las tres tradiciones que se entrecruzan en su metodología (dos lecturas de Nietzsche y la crítica literaria latinoamericana), es difícil saber si se trata de un libro sobre el desencuentro entre Nietzsche y la filosofía latinoamericana, o si se trata de un libro sobre Nietzsche que, en el camino y con métodos nietzscheanos, hace una lectura de la relación de América Latina con la obra de Nietzsche. En cualquier caso, no se desmiente la tesis central acerca del desencuentro, ni se disminuye la potencia de lectura que dicha noción ofrece.

Quizá un poco más de historia y un poco menos de genealogía le hubieran permitido a Sánchez Lopera no solo elaborar un archivo más grande, en el que pensadores como Nicolás Gómez Dávila o Julio Enrique Blanco (por referir a dos colombianos) hubieran mostrado otros aspectos del contacto de pensadores locales con Nietzsche. Quizá un poco más de historia hubiera podido explicar la diferencia en la lectura que hace de Nietzsche Rafael Gutiérrez Girardot, quien, como Gómez Dávila, tuvo un importante contacto con Europa, uno mucho más intenso que cualquier otro pensador colombiano en ese entonces; contacto que, por lo demás, podría explicar el Nietzsche de Gutiérrez Girardot, tanto como su imagen de la literatura latinoamericana al margen del Boom.

En síntesis, el libro de Sánchez Lopera ofrece una aguda lectura panorámica, pero no sistemática, de la filosofía en el subcontinente durante el siglo XX, a través del concepto de desencuentro. Así se desmarca de la diferenciación estándar entre el proyecto de la filosofía latinoamericana y el de los normalizadores, para unirlos con la expresión "filosofía mayoritaria", un término en el que también incluye a buena parte de la producción literaria atada al Boom. Nibilismo y verdad usa, en una alusión explícita a la obra de Deleuze, la noción de filosofía mayoritaria para agrupar el carácter reactivo, revictimizador y de rechazo al pasado, de esa producción escrita en frentes tan diversos como las tres tradiciones que cruza. Desde el punto de vista de la literatura, lo mayoritario aparece por vía de la crítica literaria. Sánchez Lopera logra inscribir en una dimensión filosófica la lectura, más bien sociológica según mi juicio, que hizo Rafael Gutiérrez Girardot de la cultura en el subcontinente. Una lectura que en su primer impulso y gracias a 
su paso por la obra de Nietzsche le permitió visibilizar una tradición literaria capaz de sortear los desencuentros con Nietzsche y negar el carácter telúrico que la filosofía latinoamericana se había arrogado como cosa propia ${ }^{2}$; un telurismo determinante en el Boom y del que se distancian escritores como Roberto Bolaño y Jorge Luis Borges. Filosóficamente, lo mayoritario se manifiesta como una reacción restauradora de los daños que otros hicieron en la región desde la Conquista. También se manifiesta en la recurrencia a la victimización:

Sabemos que la Conquista, y la dominación imperial, han sido una realidad geopolítica, sanguinaria y atroz. La paradoja sin embargo es que, frente a la magnitud del desgarramiento de la Conquista y la dominación imperial, en el caso de la filosofía latinoamericana mayoritaria se haya optado por una filosofía de la reconciliación, la otredad, de la no dominación en sus vertientes radicales: a saber, por un trastocamiento $[s i c]$ de la filosofía y la política en ética (Sánchez Lopera, 2018, pp. 79-80).

Finalmente, además de la reacción y la victimización, el déficit que las historias de la filosofía latinoamericana diagnostican es otro de esos indicios que nos muestran no solo el carácter mayoritario de la filosofía de la región, sino su sumisión a unas maneras de proceder tomadas de Europa. Maneras de proceder que, en una expresión de su carácter reactivo, se constituyeron en un proyecto por identificar un "núcleo mítico-ontológico", un auténtico ser latinoamericano, una reestructuración del discurso metafísico. Es esta filosofía mayoritaria y hegemónica latinoamericana la que habría dejado una impronta moral sobre el oficio en el presente; una impronta que Sánchez Lopera nos invita a reescribir con su libro.

2 En la Crítica de la razón latinoamericana, acta de defunción del proyecto de la filosofía latinoamericana, Castro-Gómez (1996) muestra que la defensa del carácter telúrico de la región no fue más que un efecto de la incapacidad de la filosofía latinoamericana de afirmarse a sí misma, de una reactividad que la llevó a verse como lo otro de Europa justo en su condición telúrica, esto es, en su vinculación con la tierra y las emociones y en oposición a una Europa abstracta y racional. 


\section{Referencias}

Castro-Gómez, S. (1996). Crítica de la razón latinoamericana. Barcelona: Puvill Libros.

López Jiménez, C. A. (2018). El terreno común de la escritura. La filosofía en Colombia 1892-1910. Bogotá: Editorial Javeriana.

Sánchez Lopera, A. (2018). Nibilismo y verdad: Nietzsche en América Latina. Oxford: Peter Lang.

Carlos Arturo López Jiménez

Pontificia Universidad Javeriana carloslopez@javeriana.edu.co 